\title{
Evaluation of the Impact of the Writing Program on Student Learning
}

\author{
Su-Ching Lin \\ Graduate Institute of Education, National Changhua University of Education, Taiwan \\ Tel: 886-919-089-047Ｅ-mail: sclin@cc.cnuc.edu.tw
}

Ying-Ling Chen

School of Chinese Medicine, China Medicine University, Taiwan

Tel: 886-975-813-940Ｅ-mail: lingcmu@mail.cmu.edu.tw

Received: September 12, 2019 Accepted: October 12, 2019 Published: October 14, 2019

doi: 10.5296/jsss.v7i1.15615

URL: https://doi.org/10.5296/jsss.v7i1.15615

\begin{abstract}
The purpose of this study was to evaluate the impact of the Chinese Writing Program of Self-Regulated Development Strategy (SRSDWP) on student learning. With that aim, two-groups were tested in an experimental design with comparison of scores of writing self-efficacy, writing self-regulated strategy, and writing motivation. Results between the experimental group and control group were examined to assess the impact of SRSDWRP on students' learning. The SRSDCWP is based on the teaching model of self-regulated strategy development (SRSD) that consists of six instructional steps of developing background knowledge, discussing, modeling, memorizing, supporting, and independent performance. Participants consisted of 105 eighth graders from one junior high school located in central Taiwan divided into 50 students in the experimental group who attended the SRSDCWP, and 55 students in the control group who were not submitted to the intervention program. Three units of teaching materials were designed and implemented for 12 weeks. Two groups with a similar background and life/ schooling experience were taught by the same Chinese literature teacher and received writing instruction for 45 minutes in a total of 135 min per week. Data were collected through students' writing self-efficacy scale, self-regulated strategy scale, and motivation scale. Data were analyzed using descriptive statistics of distribution frequencies, percentages, mean values, standard deviations and inferential statistic using ANCOVA. The results revealed that the scores of the experimental group regarding students' writing
\end{abstract}


self-efficacy scale, self-regulated strategy scale, and motivation scale were significantly higher than those of the control group. The study concluded that the SRSDCWP provided positive influence on students' writing self-efficacy, self-regulated strategies, and motivation.

Keywords: program evaluation, self-regulated strategy development, writing self-efficacy, writing self-regulated strategy, writing motivation

\section{Introduction}

Writing program has always been the focus of the language arts. Through the instruction process, writing can train students to integrate expression, patrols collection, organization, reflection, criticism, appreciation, social cognition, and even enhance academic performance. In other words, the abilities cultivated by writing instruction not only contribute to students' daily life but also benefit the future development of their workplace (Fitzgerald, 2013; Harris \& Graham, 2009). However, many secondary school students in Taiwan fear writing and have no interest in writing classes due to the complexity and difficulty associated with the development of this skill, resulting in the worsening of writing abilities of these students. Based on the Psychological and Educational Testing Research and Development Center in Taiwan (2013), the frequent shortcomings of the writing of secondary school students include lack of organized structure, the imprecise use of words, wrong spellings, and incorrect punctuation. According to Chen's observation (2004), students did not know what to write and how to write and this is a major reason to the secondary school students' poor writing in Taiwan. Therefore, an instructor should teach his/ her students effective writing strategies to help students to overcome the negative feeling of writing and enhance writing performance.

There are many writing strategies. One of them is Self-Regulated Strategy Development (SRSD) developed by Karen Harris and Steve Graham, which is designed to deal with the complexity of writing and to address writing difficulty, further to develop students' positively writing motivation and writing self-efficacy (Harris, Graham, \& Mason, 2003; Santangelo, Harris, \& Graham, 2008). SRSD derives from the theory of self-regulated learning theory (SRL). SRL theory presented by Zimmerman (1986) shows how learners manage their learning processes by application of strategy, attribution, motivation, and monitor is regarded as the key factors to the success or failure of students' learning. SRL is a cyclical process, wherein students plan for a task, the instructor monitors their performance and then students reflect on their outcome. The cycle then repeats as the student uses the reflection to adjust and prepare for the next task. The process is not one-size-fits-all; it should be tailored for individual students and specific learning tasks (Zimmerman, 2002).

The SRSD is an intervention designed to improve students' writing skills through a six-step process and teaches students specific self-regulated skills. Self-regulated skills are composed of four strategies, including self-instruction, goal-setting, self-monitoring, and self-reinforcement. The six steps of SRSD, developing background knowledge, discussing, modeling, memorizing, supporting, and independent performance, can be re-arranged, re-combined, revisited, re-modified or even omitted, depending on students' needs. Along with the teaching stages, the responsibility of writing is gradually transferred to the individual student himself/herself from the peer group (Fitzgerald, 2013; Harris, Graham, Mason, \& 
Friedlander, 2008; Sandmel et al., 2009).

Research has suggested benefits from the SRSD for students writing. A large body of evidence shows that SRSD teaching model not only improve the writing length, learning attitude and writing quality of special students (Harris, Graham, \& Adkins, 2015; Reid, Hagaman, \& Graham, 2014), but also greatly benefits general students with different writing levels (Festas, Oliveira, Rebelo, Damiao, Harris, \& Graham, 2015; Harris \& Graham, 2009; Wong, Hoskyn, Jai, Ellis, \& Watson, 2008). Recently, several studies conducted in Taiwan confirmed SRSD teaching model can enhance students' writing quality in elementary school level (Shan, 2006; Su, 2006; Xu \& Yang, 2010), however, except Zhu's study (2016), a dearth of information represents SRSD teaching model benefits junior high schools' writing in Taiwan. Zhu's study is action research. It is necessary through various research designs to testify the impact of SRSD teaching model on secondary students' writing learning. Therefore, the current study was based on SRSD teaching model to develop SRSDWRP. Then, the study applied experiment design to investigate the impact of SRSDWRP through comparison of scores of writing self-efficacy, writing self-regulated strategies, and writing motivation between the experimental group and the control group.

\section{Research Question}

The specific research questions guiding this study were: (1) Do the experimental group students and control group students have a significant difference in the sense of self-efficacy in writing? (2) Do the experimental group students and control group students have a significant difference in the sense of writing self-regulated strategy? (3) Do the experimental group students and control group students have a significant difference in the sense of writing motivation?

\section{Methodology}

\subsection{Participants and Research Design}

The study applied a quasi-experimental design (shown in Table 1) to evaluate the impact of SRSDCWP on students' learning. SRSDCWP composed of 3 units and had been implemented for 12 weeks. The teaching model of SRSDCWP majorly includes six instructional steps: Developing background knowledge, discussing it, modeling it, memorizing it, supporting it, and independent performance. The participants consisted of 105 students from a junior high school in central Taiwan. They were divided into an experimental group and a control group. The experimental group, comprising 50 students (22 girls and 28 boys), received SRSDCWP intervention that lasted 45 minutes for a total of 180 min per week. The control group, consisting of 55 students (27 girls and 28 boys) who did not take any such intervention program. However, two groups were taught by the same Chinese literature teacher and with a similar background and life experience of schooling before and received the same amount of teaching time. The quasi-experimental design of SRSDCWP was shown in Table 1. 
Table 1. The quasi-experimental design of SRSDCWP

\begin{tabular}{llll}
\hline Group & Pre-test & Treatment & Posttest \\
\hline Experimental group & O1 & $\mathrm{X}$ & O3 \\
Control group & O2 & & O4 \\
\hline
\end{tabular}

O1, O2: Both the experimental group and control group are administered by the Pre-test of the Writing Self-Efficacy Scale (WSES), Writing Self-Regulated Strategy Scale (WSRSSS), and Writing Motivation Scale (WMS) before treatment.

$\mathrm{X}$ : represented treatment in which the experimental group accepted SRSDCWP, while the control group accepted the traditional instruction.

O3, O4: Both the experimental group and control group were administered by the post-test of the WSES, WSRSSS, and WMS after treatment.

In this study, interference variables included homogeneity of experimental group and control group, the instructor, teaching materials, amount of teaching time, and the same time of pre-test and post-test. This study applied the following strategies to control interference variables.

First of all, all of the participants, including the experimental group and control group, were junior high school students of the same grade in the same school, with a similar social and economic background and life experience, and the number of students and gender distribution in the two groups was similar. Generally speaking, the background of the two groups was the same.

Second, the study examined whether or not the experimental group and control group were homogeneity in WSES, WSRSSS, and WMS by using analysis of Levene's test and analysis of regression coefficient homogeneous test.

Third, to avoid the result influenced by teachers' experience, background, and personal characteristics, the experimental group and control group were taught by the same teacher.

Fourth, topics and types of writing for the two groups were the same. The only difference was the teaching method. The experimental group adopted the SRSD teaching model, while the control group implemented the traditional teaching method.

Fifth, the amount of teaching time and progress for the two groups under were the same, which were under the school schedule.

Sixth, the pre-test and post-test for the two groups were completed within the same week, and the teacher used the same testing procedures and guidance to avoid the test factor to impact experimental results.

\subsection{Instruments}

Three research instruments, Writing Self-Efficacy Scale (WSES), Writing Self-Regulated Strategy Scale (WSRSSS), and Writing Motivation Scale (WMS) were developed in this study based on previous studies. 
The first instrument, WSES with 11 items, was designed to measure two sub-factors, including writing skill (WS) of self-efficacy (6 items) and writing task (WT) of self-efficacy ( 5 items). Students were asked to rate the items on a five-point Likert scale anchoring at 1, 2, 3,4 , and 5 (from strongly disagree to strongly agree). The factor analysis made on data obtained by WMS in the current application reveals that each item in all subscale produced factor loadings was 62.24\%. The overall internal consistency (Cronbach's $\alpha=.92$ ) for the scale in the current sample was good. The Cronbach's $\alpha$ for the two subscales were .86 and .87 , indicating good internal consistencies of the items within each subscale.

The second research instrument, WSRSSS with 28 items, was designed to measure five strategic applications toward cognitive regulation (CR, 8 items), motivated regulation (MR, 8 items), affective regulation (AR, 4 items), behavioral regulation (BR, 4 items), and environmental regulation (ER, 4 items). Students were asked to rate the items on a five-point Likert scale anchoring at 1, 2, 3, 4, and 5 (from strongly disagree to strongly agree). The factor analysis made on data obtained by WSRSSS in the current application reveals that each item in all subscale dimensions produced factor loadings was $66.17 \%$. The overall internal consistency (Cronbach's $\alpha=.94$ ) for the scale in the current sample was good. The Cronbach's $\alpha$ for the five subscales ranged from .83 to .90 , indicating good internal consistencies of the items within each subscale.

The third research instrument, WMS with 17 items, was designed to measure three dimensions: Writing interests (WI, 6 items), Writing feeling (WF, 5 items), and importance and utility of writing (IUW, 6 items). Students were asked to rate the items on a five-point Likert scale anchoring at 1,2, 3, 4, and 5 (from strongly disagree to strongly agree). The factor analysis made on data obtained by WMS in the current application reveals that each item in all subscale dimensions produced factor loadings was $79.13 \%$. The overall internal consistency (Cronbach's $\alpha=.89$ ) for the scale in the current sample was good. The Cronbach's $\alpha$ for the three subscales ranged from .88 to .97 , indicating good internal consistencies of the items within each subscale.

\subsection{Data Collection and Analysis}

During the research period, the data were collected through WSES, WSRSSS, and WMS. The statistical program SPSS 22.0 for windows was used for data analysis. First of all, three composite scores of WSES, WSRSSS, and WMS were computed for each respondent by adding the scores. Results were analyzed using descriptive statistics in terms of distribution frequencies, percentages, mean values, and standard deviations. Inferential statistics were conducted using analysis of one-way covariance (one-way ANCOVA). All statistical tests used to address the questions in this study used .05 as the minimum alpha level.

\section{4 . Results and Discussion}

\subsection{The Impact of the SRSDCWP on Students' Writing Self-Efficacy}

The current study used the teaching method as an independent variable and used the post-test of overall and subscales of WSES as dependent variables. The steps in ANCOVA were demonstrated as follows. 


\subsubsection{Testing of Homogeneity of Variance}

Table 2 indicated analysis results of testing of homogeneity of variance, which indicated after Levene's test, at the overall level $(F=.31, p=.58)$, writing skill level $(F=2.29, p=.13)$, and writing task level $(F=.01, p=.93)$, since $\mathrm{p}$-value greater than $.05=\alpha$, we could not reject the null hypothesis, and concluded there was no significant difference between these two groups, which satisfied the homogeneity of variances assumption.

Table 2. Teaching methods in the WSES pre-test analysis of Levene's test

\begin{tabular}{lllll}
\hline level & $F$ & $d f 1$ & $d f 2$ & $p$ \\
\hline WS & 2.29 & 1 & 103 & .13 \\
WT & .01 & 1 & 103 & .93 \\
overall & .31 & 1 & 103 & .58 \\
\hline
\end{tabular}

Note. $W S=$ writing skill; $W T=$ writing task

\subsubsection{Testing of Regression Coefficient Homogeneity}

Table 3 revealed that the teaching method of regression coefficient homogeneous test results within the Group (teaching methods $\times$ pre-test scores of overall scale and subscales of WSES), the $p$-value was greater than.05, significantly, the slope of the regression of the same, which indicates WSES and subscale measured before and after the relationship would not be different due to different teaching methods, regression coefficient homogeneous test assumed within the subject group, so ANCOVA analysis would be appropriate.

Table 3. Teaching methods in WSES post-test analysis of regression coefficient homogeneous test

\begin{tabular}{lllllll}
\hline L & SV & $S S$ & $d f$ & $M S$ & $F$ & $p$ \\
\hline WS & T * pre-test & 7.19 & 1 & 7.19 & .59 & .44 \\
& ER & 1231.69 & 101 & 12.19 & & \\
& SM & 50545.00 & 105 & & & \\
WT & T * pre-test & 7.08 & 1 & 7.08 & .59 & .44 \\
& ER & 1209.68 & 101 & 11.98 & & \\
& SM & 32473.00 & 105 & & & \\
OA & T $*$ pre-test & 5.81 & 1 & 5.81 & .15 & .70 \\
& ER & 3986.62 & 101 & 39.47 & & \\
& SM & 163144.00 & 105 & & & \\
\hline
\end{tabular}

Note. $L=$ level; $S V=$ Sources of variation; treatment ${ }^{*}$ pre-test $=T^{*}$ pre-test; $E R=$ error; $S M=$ sum; OR=overall 


\subsubsection{Analyses of One-way ANCOVA}

The analyses of results of one-way ANCOVA presented in table 4 and table 5, showed significant overall main group effects of the overall level $(F=118.79, \eta 2=.53, p<.001)$, writing task level $(F=97.63, \eta 2=.47, p<.001)$, and writing task level $(F=120.26, \eta 2=.53$, $p<.001$ ), which indicated significant differences between the experimental and control groups on the scores of WSES. That is, while the pre-test scores controlled, the experimental group outperformed the control group in post-test scores of overall scale and subscales in WSES.

Table 4. Teaching methods in adjusted means of the WSES post-test

\begin{tabular}{llllll}
\hline & & & & \multicolumn{2}{l}{$95 \% \mathrm{CI}$} \\
\cline { 5 - 6 } Level & Treatment & $M$ & $S D$ & $L L$ & $U L$ \\
\hline WS & EG & 25.24 & .58 & 24.08 & 26.40 \\
& CG & 17.47 & .56 & 16.37 & 18.58 \\
WT & EG & 20.61 & .46 & 19.70 & 21.52 \\
& CG & 13.71 & .44 & 12.84 & 14.58 \\
OA & EG & 45.87 & .98 & 43.93 & 47.81 \\
& CG & 31.20 & .94 & 29.35 & 33.06 \\
\hline
\end{tabular}

Note. $E G=$ experimental group; $C G=$ control group; $C I=$ confidence interval; $L L=$ lower level; $U L=$ upper level.

Table 5. Teaching methods in the WSES post-test analysis of one-way ANCOVA

\begin{tabular}{llllllll}
\hline L & SV & $S S$ & $d f$ & $M S$ & $F$ & $\eta^{2}$ & $p$ \\
\hline WS & T & $* 1569.05$ & 1 & 1569.05 & 93.67 & .47 & .00 \\
& post-test & & & & & & \\
& ER & 1708.65 & 102 & 16.75 & & & \\
& SM & 50321.25 & 105 & & & & \\
WT & T & $* 1218.09$ & 1 & 1218.09 & 120.26 & .53 & .00 \\
& post-test & & & & & & \\
& ER & 1033.13 & 102 & 10.13 & & & \\
& SM & 32564.00 & 105 & & & & \\
OA & T & $* 549.13$ & 1 & 5549.13 & 118.79 & .53 & .00 \\
& post-test & & & & & & \\
& ER & 4764.73 & 102 & 46.71 & & & \\
& sum & 163193.00 & 105 & & & & \\
\hline
\end{tabular}

$* * * p<.001$.

Note. $L=$ level; $S V=$ Sources of variation; treatment $*$ pos-test $=T^{*}$ pos-test; $E R=$ error; SM=sum; OA=overall

Based on the above analyses, this study confirmed that the SRSDCWP provided remarkable positive influences on students' writing self-efficacy in this study. Possible causes of such 
results might be that the teacher taught experimental group students to use self-regulation strategies focusing on goal setting, self-instruction, self-assessment and self-monitoring, and self-reinforcement during instruction process. This might be causes of improving writing skills, finishing writing task, and enhance self-efficacy of writing.

\subsection{The Impact of the SRSDCWP on Students'Application of Writing Self-regulated Strategy}

The current study used the teaching method as an independent variable and used the post-test of overall and subscales of WSRSSS as dependent variables. The steps in ANCOVA were demonstrated as follows.

\subsubsection{Testing of Homogeneity of Variance}

Table 6 indicated analysis results of testing of homogeneity of variance, which indicated after Levene's test, at the overall level $(F=.26, p=.61)$, cognitive regulation level $(F=1.11, p$ $=.29)$, motivate regulation level $(F=.02, p=.89)$, affective regulation level $(F=3.50, p=.06)$, behavioral regulation level $(F=1.31, p=.26)$, and environmental regulation level $(F=.83, p$ $=.37$ ), since $\mathrm{p}$-value greater than $.05=\alpha$, we could not reject the null hypothesis, and concluded there was no significant difference between these two groups, which satisfied the homogeneity of variances assumption.

Table 6. Teaching methods in the WSRSSS pre-test analysis of Levene's test

\begin{tabular}{lllll}
\hline level & $F$ & $d f 1$ & $d f 2$ & $p$ \\
\hline CR & 1.11 & 1 & 103 & .29 \\
MR & .02 & 1 & 103 & .89 \\
AR & 3.50 & 1 & 103 & .06 \\
BR & 1.31 & 1 & 103 & .26 \\
ER & .83 & 1 & 103 & .37 \\
OA & .26 & 1 & 103 & .61 \\
\hline
\end{tabular}

Note: $C R=$ cognitive regulation; $M R=$ motivate regulation; $A R=$ affective regulation; behavioral regulation; $E R=$ environmental regulation

\subsubsection{The Test of Regression Homogeneity}

Table 7 revealed that the teaching method of regression coefficient homogeneous test results within the group (teaching methods $\times$ pre-test scores of overall scale and subscales of WSRSSS), the p-value of the other levels was greater than.05, significantly, the slope of the regression of the same, which indicates WSRSSS and subscale measured before and after the relationship would not be different due to different teaching methods, regression coefficient homogeneous test assumed within the subject group, so ANCOVA analysis would be appropriate. 
Table 7. Teaching methods in WSRSSS post-test analysis of regression coefficient homogeneous test

\begin{tabular}{|c|c|c|c|c|c|c|}
\hline $\mathrm{L}$ & SV & $S S$ & $d f$ & $M S$ & $F$ & $p$ \\
\hline \multirow[t]{3}{*}{$\mathrm{CR}$} & $\mathrm{T}^{*}$ pre-test & 7.58 & 1 & 7.58 & .224 & .64 \\
\hline & ER & 3409.13 & 101 & 33.75 & & \\
\hline & $\mathrm{SM}$ & 92409.00 & 105 & & & \\
\hline \multirow[t]{3}{*}{ MR } & $\mathrm{T}^{*}$ pre-test & 71.90 & 1 & 71.90 & 2.53 & .12 \\
\hline & ER & 2874.03 & 101 & 28.46 & & \\
\hline & SM & 87032.00 & 105 & & & \\
\hline \multirow[t]{3}{*}{ AR } & $\mathrm{T}^{*}$ pre-test & 19.00 & 1 & 19.00 & 2.01 & .16 \\
\hline & ER & 953.80 & 101 & 9.44 & & \\
\hline & SM & 22304.00 & 105 & & & \\
\hline \multirow[t]{3}{*}{$\mathrm{BR}$} & $\mathrm{T} *$ pre-test & 44.65 & 1 & 44.65 & 3.67 & .06 \\
\hline & ER & 1228.57 & 101 & 12.16 & & \\
\hline & SM & 26395.00 & 105 & & & \\
\hline \multirow[t]{3}{*}{ ER } & $\mathrm{T}^{*}$ pre-test & 35.29 & 1 & 35.29 & 3.19 & .08 \\
\hline & ER & 1119.02 & 101 & 11.08 & & \\
\hline & SM & 24279.00 & 105 & & & \\
\hline \multirow[t]{3}{*}{ OR } & $\mathrm{T} *$ pre-test & 283.68 & 1 & 283.68 & .822 & .37 \\
\hline & ER & 34868.28 & 101 & 345.23 & & \\
\hline & SM & 1126069.00 & 105 & & & \\
\hline
\end{tabular}

Note: L=level; $S V=$ Sources of variation; treatment $*$ pre-test $=T^{*}$ pre-test; $E R=$ error; SM=sum

\subsubsection{Analysis of One-Way Covariance (one-way ANCOVA)}

Due to environmental regulation level of WSRSSS against regression homogeneity, so the analysis of one-way ANCOVA would not include environmental regulation level. The analyses of results of one-way ANCOVA as shown in table 8 and table 9, showed significant overall main group effects of the overall level $(F=111.19, \eta 2=.54, p<.001)$, and levels of cognitive regulation $(F=73.81, \eta 2=.42, p<.001)$, motivate regulation $(F=117.40, \eta 2=.56$, $p<.001)$, affective regulation $(F=96.12, \eta 2=.51, p<.001)$, and behavioral regulation $(F=63.98, \eta 2=.38, p<.001)$, which indicated significant differences between the experimental and control groups on the scores of the overall scale and subscales of WSRSSS. Results showed that the experimental group performed significantly better than the control group in the application of writing regulation strategies of cognition, motivation, affection, and behaviors. That is, while the pre-test scores controlled, the experimental group outperformed the control group in post-test scores of overall scale and subscales in WSRSSS. 
Table 8. Teaching methods in adjusted means of the WSRSSS post-test

\begin{tabular}{llllll}
\hline & & & & \multicolumn{2}{l}{$95 \% \mathrm{CI}$} \\
\cline { 5 - 6 } level & Treatment & $M$ & $S D$ & $L L$ & $U L$ \\
\hline CR & EG & 33.79 & .82 & 32.16 & 35.42 \\
& CG & 24.07 & .78 & 22.52 & 25.62 \\
MR & EG & 33.82 & .77 & 32.30 & 35.33 \\
& CG & 22.26 & .73 & 20.82 & 23.69 \\
AR & EG & 17.09 & .44 & 16.22 & 17.96 \\
& CG & 11.12 & .42 & 10.29 & 11.94 \\
BR & EG & 18.07 & .49 & 17.09 & 19.05 \\
& CG & 12.53 & .47 & 11.60 & 13.47 \\
OA & EG & 17.68 & .49 & 16.72 & 18.64 \\
& CG & 11.87 & .47 & 10.95 & 12.79 \\
\hline
\end{tabular}

Note. $\mathrm{EG}=$ experimental group; $\mathrm{CG}=$ control group; $\mathrm{CI}=$ confidence interval; $\mathrm{LL}=$ lower level; $\mathrm{UL}=$ upper level.

Table 9. Teaching methods in the WSRSSS post-test analysis of one-way ANCOVA

\begin{tabular}{llllllll}
\hline L & SV & $S S$ & $d f$ & $M S$ & $F$ & $\eta^{2}$ & $p$ \\
\hline CR & T* post-test & 2472.26 & 1 & 2472.26 & 73.81 & .42 & .00 \\
& ER & 3416.70 & 102 & 33.50 & & & \\
& SM & 92409.00 & 105 & & & & \\
MR & T $^{*}$ post-test & 3390.82 & 1 & 3390.82 & 117.40 & .56 & .00 \\
& ER & 2945.93 & 102 & 28.88 & & & \\
& SM & 87032.00 & 105 & & & & \\
AR & T * post-test & 916.74 & 1 & 916.74 & 96.12 & .51 & .00 \\
& ER & 972.81 & 102 & 9.54 & & & \\
& SM & 22304.00 & 105 & & & & \\
BR & T $*$ post-test & 798.68 & 1 & 798.68 & 63.98 & .38 & .00 \\
& ER & 1273.22 & 102 & 12.48 & & & \\
& SM & 26395.00 & 105 & & & & \\
ER & T $*$ post-test & 837.60 & 1 & 837.60 & 74.01 & .48 & .00 \\
& ER & 1154.31 & 102 & 11.32 & & & \\
& SM & 24279.00 & 105 & & & & \\
OR & T $*$ post-test & 38319.23 & 1 & 38319.23 & 111.19 & .54 & .00 \\
& ER & 35151.96 & 102 & 344.63 & & & \\
SM & 1126069.53 & 105 & & & & \\
\hline
\end{tabular}

$* * * p<.001$.

Note. L=level; $S V=$ Sources of variation; treatment $*$ post-test $=T^{*}$ post-test; $E R=$ error; SM=sum

Based on the above analyses, this study confirmed that the SRSDCWP provided remarkable 
positive influences on students' application of writing self-regulated strategies except for environmental regulation in the case study. Possible causes of such results might be that SRSD teaching model could enhance students' cognition, motivation, affection, behaviors, and environmental regulations during the writing process.

\subsection{The Impact of the SRSDCWP on Students' Writing Motivation}

The current study used the teaching method as an independent variable and used the post-test of overall and subscales of WMS as dependent variables. The steps in ANCOVA were demonstrated as followings.

\subsubsection{Testing of Homogeneity of Variance}

Table 10 indicated analysis results of testing of homogeneity of variance, which indicated after Levene's test, at the overall level $(F=1.53, p=.22)$, writing interest $(F=1.89, p=.17)$, writing feeling $(F=.23, p=.17)$, and importance and utility $(F=.99, p=.32)$, since p-value greater than $.05=\alpha$, we could not reject the null hypothesis, and concluded there was no significant difference between these two groups, which satisfied the homogeneity of variances assumption.

Table 10. Teaching methods in the WMS pre-test analysis of Levene's test

\begin{tabular}{lllll}
\hline level & $F$ & $d f 1$ & $d f 2$ & $p$ \\
\hline WI & 1.89 & 1 & 103 & .17 \\
WF & .23 & 1 & 103 & .63 \\
IUW & .99 & 1 & 103 & .32 \\
overall & 1.53 & 1 & 103 & .22 \\
\hline
\end{tabular}

Note: $W I=$ writing interest; $W F=$ writing feeling; $I U W=$ importance and utility of writing

\subsubsection{The Test of Regression Homogeneity}

Table 11 demonstrated that the teaching method of regression coefficient homogeneous test results within the group (teaching methods $\times$ pre-test scores of overall scale and subscales of WMS), the p-value of the other levels was greater than.05, significantly, the slope of the regression of the same, which indicates WMS and subscale measured before and after the relationship would not be different due to different teaching methods, regression coefficient homogeneous test assumed within the subject group, so ANCOVA analysis would be appropriate. 
Table 11. Teaching methods in WMS post-test analysis of regression coefficient homogeneous test

\begin{tabular}{lllllll}
\hline L & SV & $S S$ & $d f$ & $M S$ & $F$ & $p$ \\
\hline WI & T* pre-test & 128.96 & 1 & 128.96 & 7.91 & .01 \\
& ER & 1647.00 & 101 & 16.31 & & \\
\multirow{6}{*}{ WF } & SM & 40371.00 & 105 & & & \\
& T* pre-test & 16.81 & 1 & 16.81 & .73 & .39 \\
& ER & 2315.53 & 101 & 22.93 & & \\
IUW & SM & 25735.00 & 105 & & & \\
& T* pre-test & 14.87 & 1 & 14.87 & .91 & .34 \\
& ER & 1649.52 & 101 & 16.33 & & \\
& SM & 50903.00 & 105 & & & \\
& T $*$ pre-test & 542.15 & 1 & 542.15 & 10.11 & .00 \\
& ER & 5414.58 & 101 & 53.61 & & \\
\hline
\end{tabular}

Note: L=level; $S V=$ Sources of variation; treatment ${ }^{*}$ pre-test $=T^{*}$ pre-test; $E R=$ error; SM=sum.

\subsubsection{Analysis of One-Way Covariance (one-way ANCOVA)}

Due to WI level and overall level of WMS against regression homogeneity, so the analysis of one-way ANCOVA would not include both of writing interest and overall levels. The analyses of results of one-way ANCOVA as shown in table 12 and table 13, showed significant overall main group effects of writing feeling $(F=36.52, \eta 2=.34, p<.001)$ and importance and utility of writing $(F=131.78, \eta 2=.57, p<.001)$, which indicated significant differences between the experimental and control groups on the scores of the overall scale and subscales of WMS. Results showed that the experimental group performed significantly better than the control group in writing feeling and importance and utility of writing. That is, while the pre-test scores controlled, the experimental group outperformed the control group in these dimensions of writing motivation.

Table 12. Teaching methods in adjusted means of the WMS post-test

\begin{tabular}{llllll}
\hline & & & & & $95 \% \mathrm{CI}$ \\
\cline { 5 - 6 } level & Treatment & $M$ & $S D$ & $L L$ & $U L$ \\
\hline WF & EG & 17.21 & .65 & 15.93 & 18.49 \\
& CG & 11.56 & .68 & 10.22 & 12.90 \\
IUW & EG & 25.94 & .57 & 24.81 & 27.08 \\
& CG & 16.85 & .55 & 15.77 & 17.93 \\
\hline
\end{tabular}

Note. $\mathrm{EG}=$ experimental group; $\mathrm{CG}=$ control group; $\mathrm{CI}=$ confidence interval; $\mathrm{LL}=$ lower level; $\mathrm{UL}=$ upper level. 
Table 13. Teaching methods in the WMS post-test analysis of one-way ANCOVA

\begin{tabular}{llllllll}
\hline L & SV & $S S$ & $d f$ & $M S$ & $F$ & $\eta^{2}$ & $p$ \\
\hline WF & T* post-test $^{*}$ & 835.14 & 1 & 835.14 & 36.52 & .34 & $.00^{* * *}$ \\
& ER & 2332.33 & 102 & 22.87 & & & \\
& SM & 25735.00 & 105 & & & & \\
IUW & T * post-test & 2150.39 & 1 & 2150.39 & 131.78 & .57 & $.00^{* * *}$ \\
& ER & 1664.40 & 102 & 1664.40 & & & \\
& SM & 50903.00 & 105 & & & & \\
\hline
\end{tabular}

$* * * p<.001$.

Note: L=level; $S V=$ Sources of variation; treatment ${ }^{*}$ post-test $=T^{*}$ post-test; $E R=$ error; SM=sum

Based on the above analyses, this study confirmed that the SRSDCWP provided remarkable positive influences on students' writing feeling and perceiving importance and utility of writing in the case study. Based on previous research, even though these research had different research designs but found the same results, that is, SRSD teaching model has been shown to enhance students' feeling and perception of the importance and utility of writing. The SRSD teaching model is gaining more confidence now as an intervention to improve writing quality.

\section{Conclusion}

The purpose of this study was to examine the impact of the SRSDWRP on students' writing self-efficacy, application of the self-regulated strategies of writing, and writing motivation through experimental design to compare scores of WSES, WSRSSS, and WMS between the experimental group and control group. Of 105 participants, 50 students from the experimental group attended the SRSDCWP, whereas the control group of 55 students took no such intervention program. Three major findings were found in this study.

First, results showed that the experimental group performed significantly better than the control group in writing self-efficacy. This finding resembles that of previous studies (Graham, McKeown, Kiuhara, \& Harris, 2012; Harris \& Graham, 2009) and also support claims of Zimmerman (1998), in that SRL is an active and self-directed process. The writers can covert cognition, emotion, action, and situational context factors into writing skills, including choosing the right vocabularies, using correct grammatical structure, using punctuation correctly, extending the sentence into paragraphs, articles, and using all kinds of rhetorical techniques to modify articles.

Second, the experimental group performed significantly better than the control group in the application of writing regulation strategies of cognition, motivation, affection, behaviors, and environment. This finding was consistent with those of previous studies (Lin, Wu, \& Tsai, 2018; Shan, 2006; Su, 2006; Xu \& Yang, 2010; Zhu, 2016).

Third, results showed that the experimental group performed significantly higher than the 
control group in writing feeling and importance and utility of WMS. This finding was consistent with those of previous studies (Benedek et al., 2014; Festas et al.,2015; Graham et al, 2012; Hacker et al., 2015; Harris \& Graham, 2009; Shan, 2006) even though these previous studies either used qualitative research or action research, which is different research design with the current study, using two-groups experimental design, is different with the current study.

\section{Acknowledgment}

The research is financed by the Ministry of Science and Technology, Taiwan. No. MOST 105-2410-H-018-017-MY2.

\section{References}

Chen, Y. (2004). Retrospect and prospect of writing research in Taiwan. In T. Wenxing (Ed.), a new direction of curriculum and teaching (pp. 245-304). Taipei City, Taiwan: Psychology Publication.

Festas, I., Oliveira, A., Rebelo, J., Damiao, M., Harris, K., \& Graham, S. (2015). Professional development in self-regulated strategy development: Effects on the writing performance of eighth grade Portuguese students. Contemporary Educational Psychology, 40, 17-27. https://doi.org/10.1016/j.cedpsych.2014.05.004

Fitzgerald, J. (2013). Struggling writers: Constructing their instruction: What and how. Annals of Dyslexia, 63, 80-95.

Graham, S., McKeown, D., Kiuhare, S., \& Harris, K. R. (2012). A meta-analysis of writing instruction for students in the elementary grades. Journal of Educational Psychology, 104, 879-896. https://doi.org/10.1037/a0029939

Hacker, D. J., Dole, J. A., Ferguson, M., Adamson, S., Roundy, L., \& Scarpulla, L. (2015). The short-term and maintenance effects of self-regulated strategy development in writing for middle school students. Laura-Reading \& Writing Quarterly, 31(4), 351-372. https://doi.org/10.1080/10573569.2013.869775

Harris, K. R., Graham, S. \& Adkins, M., (2015). Practice-based professional development and self-regulated strategy development for Tier 2, at-risk writers in second grade. Contemporary Educational Psychology, 40, 5-16. https://doi.org/10.1016/j.cedpsych. 2014.02.003

Harris, K. R., Graham, S., \& Mason, L. (2003). Self-regulated strategy development in the classroom: Part of a balanced approach to writing instruction for students with disabilities. Focus on Exceptional Children, 35, 1-16. https://doi.org/10.17161/fec.v35i7.6799

Harris, K. R., Graham, S., \& Mason, L. H. (2006). Improving the writing, knowledge, and motivation of struggling young writers: Effects of self-regulated strategy development with and without peer support. American Educational Research Journal, 43, 295-340. https://doi.org/10.3102/00028312043002295 
Harris, K., \& Graham, S. (2009). Self-regulated strategy development in writing: Premises, evolution, and the future. British Journal of Educational Psychology, 6, 113-135. https://doi.org/10.1348/978185409X422542

Harris, K., Graham, S., Mason, L., \& Friedlander, B. (2008). Powerful writing strategies for all students. Baltimore, MD Brookes.

Harris, K. R., \& Graham, S. (1996). Making the writing process work: Strategies for composition and self-regulation. Cambridge, MA: Brookline Books.

Hayes, J. (1996). A new framework for understanding cognition and affect in writing. In M. Levy, \& S. Ransdell (Eds.), The science of writing: Theories, methods, individual differences, and applications (pp. 1-27). Mahwah, NJ: Erlbaum.

Lin, S. C., Wu, M. S., \& Chu, Y. Y. (2017). Applying program theory and logical model to design, implement, and evaluate self-regulated strategy development program. International Journal of Advanced Research, 5(11), 697-704. https://doi.org/10.21474/IJAR01/5823

Lin, S. C., Wu, M. S., \& Tsai, Lin-Ye (2018). Applying values-engaged approach to evaluate the impact of self-regulated strategy development writing program. Journal of Studies in Education, 8(2), 115-127. https://doi.org/10.5296/jse.v8i2.12557

Psychological and Educational Testing Research and Development Center (2013). Criteria of writing test of basic academic competence for Junior high school students. Taipei, Taiwan: National Taiwan Normal University.

Reid, R., Hagaman, J. L., \& Graham, S. (2014). Using self-regulated strategy development for written expression with students with attention deficit hyperactivity disorder. Learning Disabilities: A Contemporary Journal, 12(1), 21-42.

Sandmel, K., Brindle, M., Harris, K. R., Lane, K., Graham, S., Little, A., ... Mathias, R. (2009). Making it work: Differentiating tier two writing instruction with self-regulated strategies development in tandem with school-wide positive behavioral support for second graders. Teaching Exceptional Children, 42, 22-33. https://doi.org/10.1177/0040059909 04200203

Santangelo, T., Harris, K. R. \& Graham, S. (2008). Using self-regulated strategy development to support students who have "trouble getting things into words". Remedial and Special Education, 29(2), 78-89. https://doi.org/10.1177/0741932507311636

Shan, T. (2006). Teaching and learning of the process of self-regulated writing for fifth graders (unpublished doctoral thesis). National Taiwan Normal University, Taipei, Taiwan.

$\mathrm{Su}, \mathrm{F}$. (2006). The teaching effect of composition teaching course based on SRSD model on the students of the fourth graders (unpublished Master's thesis). National Hsinchu University of Education, Hsinchu, Taiwan.

Wong, B. Y. L., Hoskyn, M., Jai, D., Ellis, P., \& Watson, K. (2008). The comparative efficacy of two approaches to teaching sixth graders opinion essay writing. Contemporary 


\section{Macrothink}

Journal of Social Science Studies

ISSN 2329-9150

2020, Vol. 7, No. 1

Educational Psychology, 33(4), 757-784. https://doi.org/10.1016/j.cedpsych.2007.12.004

Xu, Y. H., \& Yang, S. H. (2010). Detection and analysis of the fourth graders' narrative writing skills in central Taiwan. Education Records, 23, 37-82.

Zhu, Y. (2016). Action research on the application of the self-regulated strategy development model to Middle school students' composition teaching (unpublished master's thesis). National Changhua University of Education, Changhua, Taiwan.

Zimmerman, B. J. (1986). Development of self-regulated learning: Which are the key sub-process. Contemporary Educational Psychology, 16, 307-313. https://doi.org/10.1016/ 0361-476X(86)90027-5

Zimmerman, B. J. (1998) Academic studying and the development of personal skill: A self-regulatory perspective. Educational Psychologist, 33(2/3), 73-86. https://doi.org/ 10.1207/s15326985ep3302\&3_3

Zimmerman, B. J. (2002). Becoming a self-regulated learner an overview. Theory into Practice, 41, 64-70. https://doi.org/10.1207/s15430421tip4102_2

\section{Copyright Disclaimer}

Copyright for this article is retained by the author(s), with first publication rights granted to the journal.

This is an open-access article distributed under the terms and conditions of the Creative Commons Attribution license (http://creativecommons.org/licenses/by/3.0/). 